E.В.Іривалова ${ }^{1}$, H.А.Кузубовва ${ }^{1}$, T.В.Вавилова ${ }^{2}$, O.H.Tитова ${ }^{1}$

Современные возможности мониторинга и подбора антиагрегантной терапии у больных хронической обструктивной болезнью легких

1 - Научно-исследовательский институт пульмонологии СПбГМУ им. акад. И.П.Павлова: 197022, Санкт-Петербург, ул. Рентгена, 12;

2 - Санкт-Петербургская государственная медицинская академия им. И.И.Мечникова: 195067, Санкт-Петербург, Пискаревский пр., 47

E.V.Privalova, N.A.Kuzubova, T.V.Vavilova, O.N.Titova

\title{
Modern monitoring and choice of antiplatelet therapy in patient with COPD
}

\begin{abstract}
Summary
The aim of this study was to investigate the platelet activity in smokers with chronic obstructive pulmonary disease (COPD). Platelet aggregation was studied using the impedance aggregometer "Chrono-log" with ADP and collagen induction in the whole citrated blood samples. Slowing of early stages of aggregation was seen in patients with COPD. More severe COPD corresponded to more active aggregation. We also evaluated effects of acetylsalicylic acid (Cardiomagnyl) on dyspnea and lung function in patients with COPD.

Key words: chronic obstructive pulmonary disease, aggregometry.
\end{abstract}

\section{Резюме}

Целью исследования являлось изучение активности тромбоцитов у курильщиков с хронической обструктивной болезнью легких (ХОБЛ). Агрегация тромбоцитов изучалась на импедансном агрегометре Chrono-log (США) с индукцией АДФ и коллагеном в образцах цельной цитратной крови. Выявлено замедление ранних этапов агрегации у пациентов с ХОБЛ. Нарастание тяжести ХОБЛ сопровождалось повышением интенсивности агрегации. Оценивалось изменение степени одышки и вентиляционных параметров при приеме препарата ацетилсалициловой кислоты (Кардиомагнила).

Ключевые слова: хроническая обструктивная болезнь легких, агрегатометрия.

Базисная терапия при хронической обструктивной болезни легких (ХОБЛ) направлена на улучшение бронхиальной проходимости и подавление хронического воспаления, при этом она не оказывает непосредственного воздействия на процессы повреждения и репарации эндотелия. Нарушение целостности интимы сосудов, замедление кровотока, дисбаланс свертывающей и противосвертывающей систем крови сопровождают развитие воспалительного процесса в легочной ткани [1]. Однако механизм развития данных изменений остается малоизученным. В настоящее время нет единого мнения об информативности и о воспроизводимости методик оценки эндотелиальной дисфункции, а также отсутствуют четкие представления о возможностях и критериях лабораторной оценки клеток, участвующих в процессах повреждения и репарации эндотелия. Повреждение эндотелия и развитие эндотелиальной дисфункции с "обнажением" коллагена является одним из главных стимулов агрегации и адгезии тромбоцитов, запуская процессы тромбообразования и репарации капилляров [2]. Однако, несмотря на участие тромбоцитов в развитии вышеперечисленных процессов, их роль в патогенезе ХОБЛ окончательно не определена [3].

Тромбоциты, с присущей им способностью к адгезии и агрегации в местах повреждения сосудистой стенки, являются обязательными участниками как процессов поддержания нормального гемостаза, так и патологического тромбообразования [1]. Процесс активации и адгезии тромбоцитов является ответом на повреждение и направлен на восстановление целостности сосудистой стенки, однако его неконтролируемое прогрессирование может стать причиной формирования тромба внутри сосуда, а снижение интенсивности приводит к плохой репарации поврежденного участка эндотелия [4].

Современные лабораторные технологии, такие как импедансная агрегатометрия, дают принципиально новые возможности для оценки активности тромбоцитов, позволяя выявить более ранние морфологические и функциональные нарушения у больных ХОБЛ. Агрегатометрия в кардиологической практике проводится преимущественно с использованием оптико-механических коагулометров, основанных на измерении индуцированной агрегации тромбоцитов оптическим методом Борна (Born G). Принцип данного метода основан на регистрации изменений светопропускания обогащенной тромбоцитами плазмы (ОТП) и имеет ряд особенностей и недостатков. Так, агрегатометрия проводится в образцах ОТП, которая является искусственной системой и исключает влияние на активацию тромбоцитов других клеток крови. В процессе приготовления ОТП цитратную кровь центрифугируют при $200 \mathrm{~g}$ в течение 7 мин, что оказывает дополнительное механическое воздействие на тромбоциты, инициируя частичное высвобождение $\alpha$-гранул тромбоцитов еще до начала регистрации агрегатограммы [5]. 


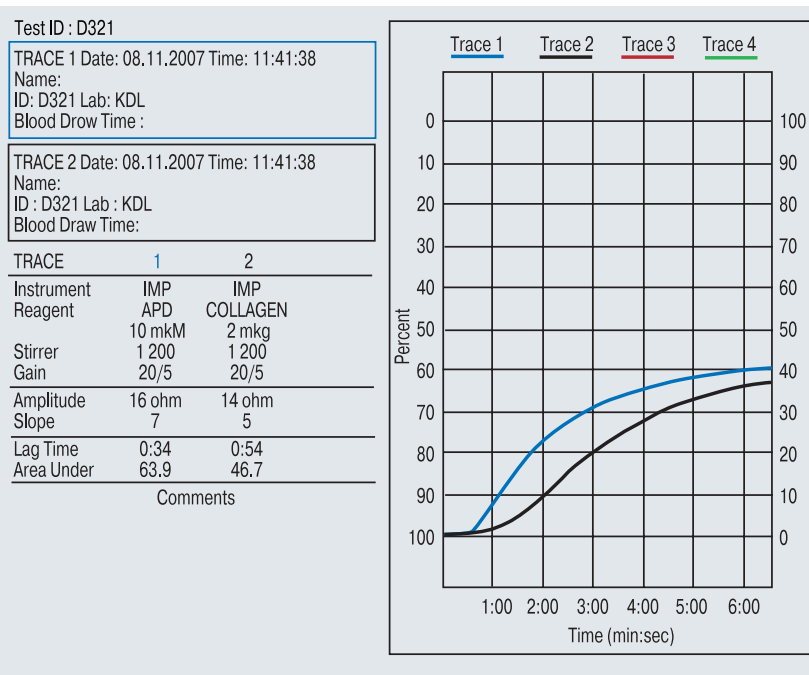

Рис. 1. Агрегатограмма курильщика с ХОБЛ

Существующие в настоящее время медицинские технологии позволяют детально исследовать процессы агрегации тромбоцитов и расширяют возможности мониторинга антиагрегантной терапии. В частности, все более широкое применение находит метод импедансной агрегатометрии, который основан на регистрации изменений электрического сопротивления в образцах цельной цитратной крови (разведение $1: 1)[6,7]$. В настоящее время он широко используется за рубежом и в России для скрининга активности тромбоцитов при мониторинге терапии антиагрегантами в кардиологической и неврологической практике [8, 9]. Изучение комплексного ответа тромбоцитов в присутствии всех клеточных и плазменных элементов крови в реальном времени - в условиях, приближенных к физиологическим, - особенно важно при обследовании пациентов с таким патогенетически сложным заболеванием, как ХОБЛ.

Отличительной особенностью метода является регистрация времени задержки агрегации (lag-фаза), как показано на рис. 1. Lag-фаза - это период от момента активации рецепторов тромбоцитов до секреции тромбоцитарных гранул, необходимый для активации фосфолипазы С и образования вторичных посредников [10].

Возможности медикаментозной коррекции изменений функциональной активности тромбоцита, клетки-участника эндотелиальной дисфункции при ХОБЛ, в настоящее время исследованы недостаточно [11]. Между тем частое сочетание ХОБЛ с кардиоваскулярной патологией $[12,13]$ диктует необходимость оценить перспективы использования антиагрегантов совместно с базисной терапией заболевания. Использование современных лабораторных методик позволит расширить представление о патогенезе заболевания и механизмах формирования нарушений микроциркуляции у больных ХОБЛ [14].

Таким образом, изучение агрегационной активности тромбоцитов и возможностей ее коррекции, а также оценка влияния препаратов ацетилсалициловой кислоты на клинические и лабораторные показатели больных ХОБЛ представляются весьма актуальными.

Исследование агрегационной активности тромбоцитов у больных ХОБЛ было проведено методом импедансной агрегатометрии с последующей оценкой влияния препарата ацетилсалициловой кислоты (Кардиомагнила) на клиническое течение заболевания, вентиляционные и лабораторные показатели.

\section{Материалы и методы}

В исследовании участвовали 108 пациентов, которые были разделены на 3 группы (табл. 1).

Диагноз ХОБЛ установлен на основании жалоб пациентов, анамнеза заболевания и жизни, объективных, функциональных и лабораторно-инструментальных данных. К моменту обследования продолжительность заболевания ХОБЛ пациентов 1-й группы составляла в среднем 4 года. Исследование проводилось в период стабильного течения заболевания. Наиболее характерными симптомами у пациентов этой группы были одышка и кашель различной интенсивности. Преобладали пациенты с тяжелой и очень тяжелой степенью одышки, согласно шкале MRC. Степень тяжести ХОБЛ оценивалась в соответствии с классификацией Глобальной инициативы по хронической обструктивной болезни легких (GOLD) пересмотра 2008 г. и основывалась на результатах клинического обследования и данных спирометрии. В 1-й группе преобладали больные со среднетяжелым $(42 \%)$ и тяжелым течением (40 \%) ХОБЛ (табл. 2).

В исследование не включались пациенты с кардиоваскулярной патологией, требующей назначения антиагрегантов и антикоагулянтов, а также с любой клинически значимой хронической патологией или с воздействием профессиональных вредностей в анамнезе.

Дизайн исследования предполагал 3 этапа. На 1-м этапе проводилось сравнительное изучение функциональных характеристик тромбоцитов между 3 группами. На 2-м этапе было выполнено исследование 34 пациентов с ХОБЛ, получавших базисную тера-

Таблища 1

Распределение больных по полу, возрасту и индексу курения, $M \pm m$

\begin{tabular}{|c|c|c|c|c|c|c|}
\hline \multirow[t]{2}{*}{ Группа } & \multirow[t]{2}{*}{ Состав группы } & \multirow[t]{2}{*}{ Число больных } & \multirow[t]{2}{*}{ Средний возраст } & \multirow[t]{2}{*}{ ИК, пачек / лет } & \multicolumn{2}{|c|}{ Пол } \\
\hline & & & & & M & ж \\
\hline 1-я & Курильщики с ХОБЛ & 64 & $61,2 \pm 1,01$ & $37,3 \pm 2,01$ & 62 & 2 \\
\hline 2-я & Курильщики без нарушения бронхиальной проходимости & 24 & $53,4 \pm 2,2$ & $28,7 \pm 2,8$ & 19 & 5 \\
\hline 3-я & Некурящие лица без бронхолегочной патологии & 20 & $54,0 \pm 3,0$ & 0 & 17 & 3 \\
\hline
\end{tabular}

Примечание: ИК - индекс курения. 
Таблица 2

Показатели спирометрии у больных ХОБЛ различной степени тяжести

\begin{tabular}{|c|c|c|c|}
\hline $\begin{array}{c}\text { Степень } \\
\text { тяжести ХОБл }\end{array}$ & ЖЕЛ, \% & Индекс Тиффно & ОФВ ${ }_{1}, \%_{\text {долж. }}$ \\
\hline$I(n=3)$ & $111,8 \pm 13,7$ & $60,9 \pm 6,8$ & $88,7 \pm 6,0$ \\
\hline$\| I(n=27)$ & $88,3 \pm 2,3$ & $58,0 \pm 1,7$ & $63,5 \pm 1,4$ \\
\hline III $(n=26)$ & $78,3 \pm 2,9$ & $42,1 \pm 1,8$ & $40,5 \pm 1,1$ \\
\hline IV (n= 8) & $58,6 \pm 2,4$ & $38,4 \pm 2,9$ & $25,2 \pm 1,0$ \\
\hline
\end{tabular}

Примечание: ЖЕЛ - жизненная емкость легких, ОФВ 1 - объем форсированного выдоха за 1-юc.

пию в соответствии с рекомендациями GOLD (2008) в течение года. Пациенты с легкой ХОБЛ получали фенотерол / ипратропиума бромид в дозе 50 мкг / 20 мкг по требованию до 4 раз в сутки, со среднетяжелой ХОБЛ - тиотропия бромид в дозе 18 мкг в сутки и фенотерол / ипратропиума бромид в дозе 50 мкг / 20 мкг по требованию 1-2 раза в сутки, с тяжелой и крайне тяжелой ХОБЛ - тиотропия бромид в дозе 18 мкг в сутки, формотерол в дозе 24мкг в сутки, беклометазона дипропионат в дозе 1000 мкг в сутки. На 3-м этапе из группы повторно обследованных пациентов с ХОБЛ были отобраны 10 курильщиков (среднее значение объема форсированного выдоха за $1-ю$ с $\left.\left(\mathrm{OФВ}_{1}\right)-38,4 \pm 5,7 \%_{\text {долж. }}\right)$ с более высокими показателями агрегации тромбоцитов. Все они продолжали получать базисную терапию, дополненную приемом Кардиомагнила в дозе 150 мг в течение месяца. Кардиомагнил представляет собой соединение ацетилсалициловой кислоты с невсасывающимся антацидом - гидроксидом магния [15].

Исследование функции внешнего дыхания (ФВД) проводилось на спирографе Pneumoscreen-2 (Erich Jaeger, Германия). Выраженность изменений оценивалась согласно градации Р.Ф.Клемента (1986). При анализе ФВД определялись жизненная емкость легких (ЖЕЛ), форсированная жизненная емкость легких (ФЖЕЛ), ОФВ 1 , индекс Тиффно $\left(\right.$ ОФВ $_{1} /$ ЖЕЛ), мгновенная объемная скорость при выдохе 20, 50, $75 \%$ ФЖЕЛ ( $\left.\mathrm{MOC}_{25}, \mathrm{MOC}_{50}, \mathrm{MOC}_{75}\right)$.

Исследование функциональной активности тромбоцитов проводилось на импедансном агрегометре Chrono-log (Chrono-log Corporation, США). В хо-

Таблица 3

Параметры агрегации тромбоцитов при исследовании методом импедансной агрегатометрии (индукция АДФ и коллагеном)

\begin{tabular}{|c|c|}
\hline $\begin{array}{l}\text { Показатель } \\
\text { агрерации }\end{array}$ & Значение для оценки функции тромбоцитов \\
\hline Амплитуда & $\begin{array}{l}\text { Сопротивление при прохождении тока через } \\
\text { образующиеся на электродах агрегаты } \\
\text { тромбоцитов после добавления индуктора } \\
\text { в кювету с кровью }\end{array}$ \\
\hline $\begin{array}{l}\text { Наклон кривой } \\
\text { агрегации }\end{array}$ & $\begin{array}{l}\text { Отражает интенсивность ответа тромбоцитов } \\
\text { на активацию индуктором }\end{array}$ \\
\hline $\begin{array}{l}\text { Время задержки } \\
\text { агрегации } \\
\text { (Lag-фаза) }\end{array}$ & $\begin{array}{l}\text { Период времени от формирования } \\
\text { монослоя тромбоцитов на электроде до начала } \\
\text { процесса агрегации после добавления } \\
\text { индуктора }\end{array}$ \\
\hline $\begin{array}{l}\text { Площадь под } \\
\text { кривой агрегации }\end{array}$ & $\begin{array}{l}\text { Интегральная характеристика функционального } \\
\text { состояния тромбоцитов за } 6 \text { мин наблюдения }\end{array}$ \\
\hline
\end{tabular}

де агрегатометрии оценивались параметры, представленные в табл. 3.

В качестве индукторов использовались аденозиндифосфат (АДФ) и коллаген производства Chrono-log Corporation (США) в дозе 10 мкМ и 2 мкг соответственно.

При статистической обработке результатов применялись критерий Манна-Уитни и коэффициент ранговой корреляции Спирмана, парный критерий Вилкоксона. Альтернативная статистическая гипотеза принималась при значении $p \leq 0,05$.

\section{Результаты}

В ходе исследования было выявлено, что в 1-й и 2-й группе курильщики имели достоверно более низкие параметры агрегации, по сравнению с показателями некурящих лиц, что отражает замедление ранних этапов формирования тромбоцитарного тромба и связано либо с нарушением реакции высвобождения, либо с меньшим содержанием гранул в тромбоците (табл. 4).

Увеличение времени задержки агрегации отражает истощение систем вторичных посредников активации тромбоцитов (АДФ, тромбоксан А2). В современных исследованиях, посвященных использованию агрегатометрии у больных с кардиоваскулярной патологией, нет сведений об изменении этого показателя. Референтные значения для данного параметра пока не определены.

Отмечалось усиление агрегационной активности по мере нарастания клинической симптоматики и вентиляционных нарушений у пациентов с ХОБЛ, что указывает на вовлечение тромбоцитов в патологический процесс. Результаты исследования ФВД у больных ХОБЛ свидетельствуют о достоверном снижении ОФВ $1(p<0,0001)$ и ЖЕЛ $(p<0,001)$ и повышении интенсивности агрегации с АДФ по мере усиления одышки $(p<0,05 ; r=-0,24)$. Снижение $\mathrm{OФB}_{1}$ сопровождалось сокращением времени задержки агрегации тромбоцитов с АДФ $(p<0,005 ; r=0,3)$, как показано на рис. 2. Снижение ОФВ 1 сопровождалось также увеличением площади под кривой агрегации с АДФ ( $p<0,05 ; r=-0,24)$ (рис. 3).

Таблица 4 Агрегационная активность тромбоцитов исследуемых групп

\begin{tabular}{|l|c|c|c|}
\multicolumn{1}{|c|}{ Показатель } & $\begin{array}{c}1 \text {-я группа } \\
(n=64)\end{array}$ & $\begin{array}{c}2 \text {-я группа } \\
(n=24)\end{array}$ & $\begin{array}{c}\text { 3-я группа } \\
(n=20)\end{array}$ \\
\hline Амплитуда с АДФ, Ом & $14,3 \pm 0,5^{*}$ & $14,4 \pm 0,6^{*}$ & $18,5 \pm 0,6$ \\
\hline $\begin{array}{l}\text { Амплитуда } \\
\text { с коллагеном, Ом }\end{array}$ & $19,4 \pm 0,5^{*}$ & $19,8 \pm 0,7^{*}$ & $22,4 \pm 0,6$ \\
\hline Наклон с АДФ & $8,7 \pm 0,4^{*}$ & $8,4 \pm 0,5^{*}$ & $13,3 \pm 0,6$ \\
\hline Наклон с коллагеном & $9,2 \pm 0,5^{*}$ & $9,0 \pm 0,4^{*}$ & $13,7 \pm 0,7$ \\
Время задержки с АДФ, с & $32,0 \pm 1,9^{*}$ & $31,0 \pm 2,0^{*}$ & $18,5 \pm 0,9$ \\
\hline Время задержки & & & \\
с коллагеном, с & $52,6 \pm 1,9$ & $49,9 \pm 3,5$ & $45,9 \pm 2,9$ \\
\hline Площадь с АДФ & $58,2 \pm 2,4^{*}$ & $57,6 \pm 2,8^{*}$ & $81,6 \pm 2,8$ \\
\hline Площадь с коллагеном & $67,9 \pm 2,3^{*}$ & $69,3 \pm 2,8^{*}$ & $84,2 \pm 3,0$ \\
\hline
\end{tabular}

Примечание: * - p<0,0001 при сравнении с 3-й группой. 


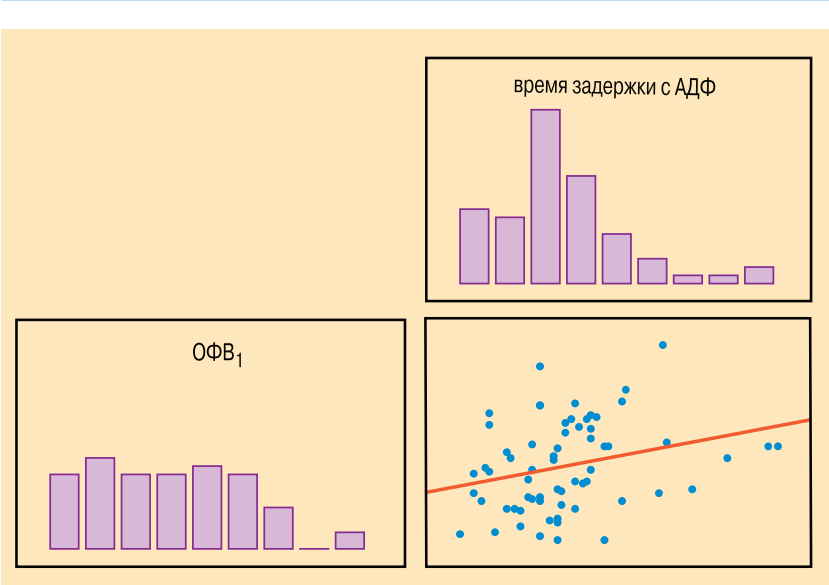

Рис. 2. Зависимость времени задержки агрегации с АДФ от ОФВ (2-мерные гистограммы и диаграмма 2-мерного рассеяния корреляции Спирмана)

Примечание: по оси X - время задержки агрегации с АДФ; по оси Y $\mathrm{OФB}_{1} ; p<0,005 ; \mathrm{R}=0,3$

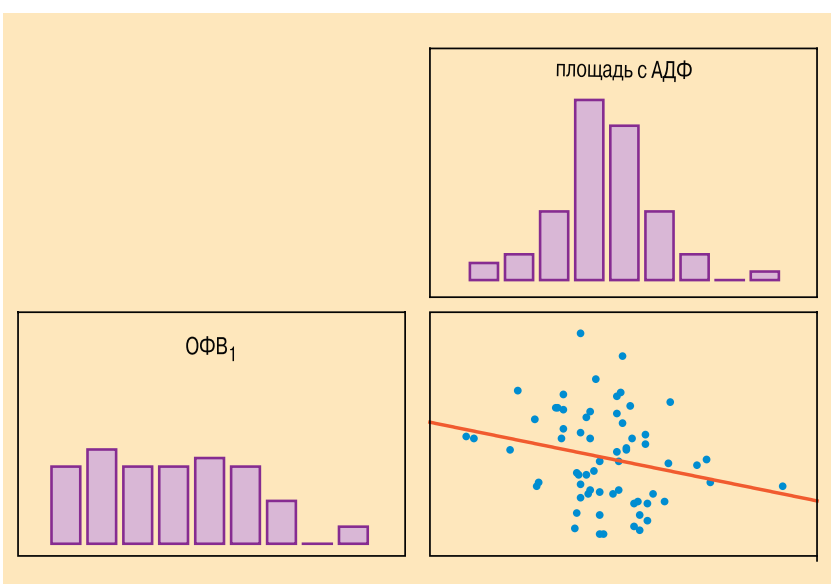

Рис. 3. Зависимость площади под кривой агрегации с АДФ от ОФВ (2-мерные гистограммы и диаграмма 2-мерного рассеяния корреляции Спирмана)

Примечание: по оси X - площадь под кривой агрегации с АДФ; по оси Y $\mathrm{O} \mathrm{B}_{1} ; p<0,05 ; \mathrm{R}=-0,24$.

Увеличение площади агрегации и уменьшение времени задержки агрегации при индукции АДФ сочетались с снижением $\mathrm{MOC}_{25}, \mathrm{MOC}_{50}$ и $\mathrm{MOC}_{75}$ $(p<0,05)$. Увеличение степени тяжести ХОБЛ сопровождалось сокращением времени задержки с АДФ $(p<0,005)$ и ростом площади под кривой с АДФ $(p<0,05)$. Отсутствовала корреляция клиникофункциональных показателей тяжести ХОБЛ с амплитудными и временными параметрами агрегации при индукции коллагеном.

Достоверных изменений вентиляционных показателей, количества эритроцитов и агрегационной тромбоцитарной активности при повторном исследовании курильщиков с ХОБЛ, получавших базисную терапию в течение года, не выявлено. Прием препарата ацетилсалициловой кислоты вызвал адекватное снижение всех средних показателей агрегационной активности тромбоцитов, достигшее достоверных значений при индукции с коллагеном $(p<0,05)$. На фоне приема антиагреганта у больных отмечалось нарастание одышки $(p<0,01)$ и ухудшение вентиляционных показателей с достоверным снижением индекса Тиффно $(p<0,05)$.

\section{Обсуждение}

Полученные результаты агрегатометрии свидетельствуют о замедлении ранних этапов формирования тромбоцитарного тромба у курильщиков обеих групп. Удлинение времени задержки агрегации отражает истощение систем вторичных посредников активации тромбоцитов (АДФ, тромбоксан А2) [10]. В современных работах, посвященных использованию агрегатометрии у больных с кардиоваскулярной патологией, нет сведений об изменении этого показателя. Среднестатистическая норма для данного параметра в настоящее время отсутствует. При оценке Lag-фазы у курильщиков обеих групп было отмечено достоверное увеличение ее продолжительности при индукции агрегации с АДФ ( $p<0,0001)$. Анализ литературных источников позволяет предположить, что удлинение этого интервала связано либо с меньшим содержанием гранул в тромбоците, либо с нарушением реакции высвобождения. Хронический воспалительный процесс сопровождается повреждением эндотелия и может вызвать увеличение доли тромбоцитов, подвергшихся обратимой активации $[1,16]$. Длительное воздействие малых доз индукторов приводит к истощению пула хранения тромбоцитов и ослаблению интенсивности реакции высвобождения гранул при повторной активации. В свою очередь, присутствие таких тромбоцитов в крови замедляет процессы репарации эндотелия вследствие уменьшения выделения тромбоцитарного фактора роста (PDGF).

Ухудшение клинических и вентиляционных показателей у больных ХОБЛ, вероятно, связано с резким снижением репарации эндотелия сосудов легких под воздействием ацетилсалициловой кислоты. Антиагрегантное действие данного препарата обусловлено необратимым блоком циклоксигеназы с подавлением синтеза и высвобождения тромбоксана A2. В результате тромбоциты на весь период своей жизни теряют способность к секреции гранул [1, 17], в т. ч. и $\alpha$-гранул, содержащих PDGF, без которого репарация эндотелия невозможна. У больных ХОБЛ ситуация усугубляется замедлением ранних этапов формирования тромбоцитарного тромба, что свидетельствует об исходном дефиците пула хранения тромбоцитов и особенно $\alpha$-гранул, играющих важную роль в формировании эндотелиальной дисфункции при ХОБЛ.

Современные антиагреганты имеют разную направленность действия, что позволяет подобрать препарат, который снижает эндогенную индукцию тромбоцитов, не блокируя высвобождение PDGF на ранних этапах формирования тромбоцитарного тромба. По эффективности с препаратами ацетилсалициловой кислоты сравнима группа тиенопиридинов, включающая в себя 2 подгруппы - препараты тиклопидина и клопидогрела. Являясь мощными ингибиторами агрегации, они не обладают ульцерогенным и диспептическим действием [18]. Применение тиклопидина ограничено длительностью развития антиагрегантного эффекта (24-48 ч). Клопидогрел, 
в отличие от тиклопидина, развивает свое действие за 2 ч и требует меньших доз для достижения терапевтического эффекта [17]. Механизм действия клопидогрела связан с селективным блоком АДФ рецепторов тромбоцитов и преимущественно подавляет поздние этапы агрегации тромбоцитов, а также образование фибриновых мостиков. Принимая во внимание полученные в ходе исследования данные по корреляции интенсивности агрегации с АДФ с выраженностью обструктивных нарушений у больных ХОБЛ, селективная блокада АДФ-рецепторов, возможно, будет способствовать улучшению микроциркуляции в легких.

\section{Заключение}

1. Импедансная агрегатометрия является адекватным методом оценки активности тромбоцитов у больных ХОБЛ, получающих антиагрегантную терапию.

2. У курильщиков табака, независимо от наличия обструктивных нарушений, изменена активность тромбоцитов с замедлением ранних этапов формирования тромбоцитарного тромба.

3. Нарастание одышки и ухудшение вентиляционных показателей у пациентов с ХОБЛ сопровождается повышением агрегационной активности тромбоцитов.

4. Базисная терапия ХОБЛ не воздействует на активность тромбоцитов и их морфологические характеристики.

\section{Литература}

1. Долгов В.В., Свирин П.В. Лабораторная диагностика нарушений гемостаза. М.: Триада; 2005.

2. Петрищев Н.Н. Дисфункция эндотелия. Причины, механизмы, фармакологическая коррекция. СПб.: Издво СПбГМУ; 2003.

3. Tsuji T., Aoshiba K., Nagai A. Alveolar cell senescence in patients with pulmonary emphysema. Am. J. Respir. Crit. Care Med. 2006; 174: 886-893.

4. Берковский А.Л., Васильев С.А., Жердева Л.В. Пособие по изучению адгезивно-агрегационной активности тромбоцитов. М.; 2000.

5. Шитикова А.С. Тромбоцитарный гемостаз. СПб.: Издво СПБГМУ; 2000. 115-164.

6. Gordge M.P., Dodd N.J., Rylance P.B., Weston M.J. An assessment of whole blood impedance aggregometry using blood from normal subjects and haemodialysis patients. Thromb. Res. 1984; 36: 17-25.

7. Morel-Kopp M.C., Aboud M., Tan C.W. et al. Whole blood impedance aggregometry detects heparin-induced thrombocytopenia antibodies. Thromb. Res. 2010; 125 (5: 234-239).
8. Hochholzer W., Trenk D., Frundi D. Whole blood aggregometry for evaluation of the antiplatelet effects of clopidogrel. Thromb. Res. 2007; 119: 285-291.

9. Svenstrup P.T., Kristensen S.R., Korsholm L. Variation and importance of aspirin resistance in patient with know cardiovascular disease. Thromb. Res. 2006; 10: 022-029.

10. Назаренко Г.И., Кишкун А.А. Клиническая оценка результатов лабораторных исследований. М.: Медицина; 2002.

11. Трапезникова А.И. Клинико-гемодинамические эффекты амлодипина и его влияние на систему гемостаза и агрегацию тромбоцитов у больных ишемической болезнью сердца в сочетании с хроническим обструктивным бронхитом. Автореф. дис. ... канд. мед. наук. Уфа; 2000

12. Чучалин А.Г. Хроническая обструктивная болезнь легких и сопутствующие заболевания. Ч. І. ХОБЛ и поражения сердечно-сосудистой системы. Рус. мед. журн. 2008; 2: 58-65.

13. Nishiyama K., Morimoto T., Furukawa Y. et al. Chronic obstructive pulmonary disease - an independent risk factor for long-term cardiac and cardiovascular mortality in patients with ischemic heart diaease. Int. J. Cardiol. 2009; 10: 1006-10013.

14. Eichhorn M.E., Ney L., Massberg S., Goetz A.E. Platelet kinetics in the pulmonary microcirculation in vivo assessed by intravital microscopy. J. Vasc. Res. 2002; 39 (4): 330-339.

15. Лупанов В.П. Роль ацетилсалициловой кислоты при вторичной профилактике атеросклероза и его сердечно-сосудистых осложнений. Рус. мед. журн. 2009; 14: 898-903.

16. Баркаган 3.С., Момот А.П. Диагностика и контролируемая терапия нарушений гемостаза. М.: Ньюдиамед; 2008.

17. Санодзе И.Д., Святов И.С., Шилов А.М. Антиагреганты современное состояние вопроса. Рус. мед. журн. 2003; 11 (9): 552-556.

18. Добровольский А.В. Клопидогрел в лечении заболеваний сердечно-сосудистой системы. Рус. мед. журн. 2009; 17 (8): 558-570.

\section{Информация об авторах}

Привалова Елена Владимировна - старший научный сотрудник лаборатории хронической обструктивной патологии легких НИИ пульмонологии СПбГМУ им. акад. И.П.Павлова; тел.: 8-911-939-05-39; e-mail: doc.priv.2@rambler.ru

Кузубова Наталия Анатольевна - д. м. н., зам. директора по научной работе, зав. лабораторией хронической обструктивной патологии легких НИИ пульмонологии СПбГМУ им. акад. И.П.Павлова; тел.: (812) 234-17-69; e-mail: kuzubova@mail.ru

Вавилова Татьяна Владимировна - д. м. н., проф. кафедры госпитальной терапии СПбГМА им. И.И.Мечникова, зав. курсом клинической лабораторной диагностики Санкт-Петербургской государственной медицинской академии им. И.И.Мечникова; тел.: (812) 786-26-54; e-mail: vtv.lab@rambler.ru

Титова Ольга Николаевна - д. м. н., директор НИИ пульмонологии СПбГМУ им. акад. И.П.Павлова; тел.: (812) 499-68-40; e-mail: titovaon @spb-gmu.ru

Поступила 22.03.11 (с) Коллектив авторов, 2011 удк 616.24-036.12-085.273 